EPJ Web of Conferences 12, 03003 (2011)

DOI: $10.1051 /$ epjconf/20111203003

(C) Owned by the authors, published by EDP Sciences, 2011

\title{
Examples of feedback, experimental and theoretical approaches for concrete durability assessment
}

\author{
M. Lion ${ }^{1, a}$, Y. Le Pape ${ }^{2}$, F. Toutlemonde ${ }^{3}$ and A. Jeanpierre ${ }^{1}$ \\ ${ }^{1}$ EDF Ceidre-TEGG, Aix-en-Provence, France \\ ${ }^{2} E D F R \& D$, Moret-sur-Loing, France \\ ${ }^{3}$ LCPC, Paris, France
}

\begin{abstract}
This paper presents some experimental data obtained from UHPFRC (Ultra-High Performance Fibre-Reinforced Concrete) being exposed for 10 years in a cooling tower and a high slag content concrete being exposed for 30 years in a marine environment. Experimental data are then used for assessing concrete durability through a theoretical approach, namely performance-based analysis. The results from the application of this approach are consistent with the penetration depth of aggressive agents measured from core samples. Finally a simulation method currently being developed by EDF is presented, which has great relevance to durability assessment.
\end{abstract}

\section{INTRODUCTION}

Electricite De France (EDF, a French Power company) is in charge of the construction and the management of an extended fleet of nuclear, hydraulic and thermal power plants covering a wide range of geographical locations, exposure and environmental conditions, times of construction or concrete mix-proportions. EDF has to guarantee the durability of its structures with regard to a specified service life. This demands for example the definition of concrete specifications for a required design service life or the evaluation of the ability of a concrete to sustain the extended service life of an existing power plant. In this context, EDF needs to increase its existing knowledge about the behavior and the ageing of in-situ concrete, based on frequent analysis of the feedback on various concretes exposed in a range of different environments. Two case studies of in-situ concrete feedback investigation will be discussed in the paper, the purpose of which is to present some of the experimental and theoretical methods adopted by EDF for a concrete durability assessment.

\section{UHPFRC FEEDBACK}

This case study is based on a nuclear power plant in Eastern France, constructed in the 1980's. Crossflow cooling towers (hot dripping water being cooled through an ascending air flow) showed mild instances of degradation caused by the aggressive environment. Superstructures supporting the laths favouring the dispersion of water drops showed early signs of damage, which led EDF to improve the thermal exchange device. This renovation, initiated in the mid 1990's, consisted of subdividing the initial thermal exchange device into two superimposed parts (Figure 1). Thus an additional structure to be integrated with the original was designed. For durability reasons and also because of the desire to

ae-mail: maxime.lion@edf.fr

This is an Open Access article distributed under the terms of the Creative Commons Attribution-Noncommercial License 3.0, which permits unrestricted use, distribution, and reproduction in any noncommercial medium, provided the original work is properly cited. 


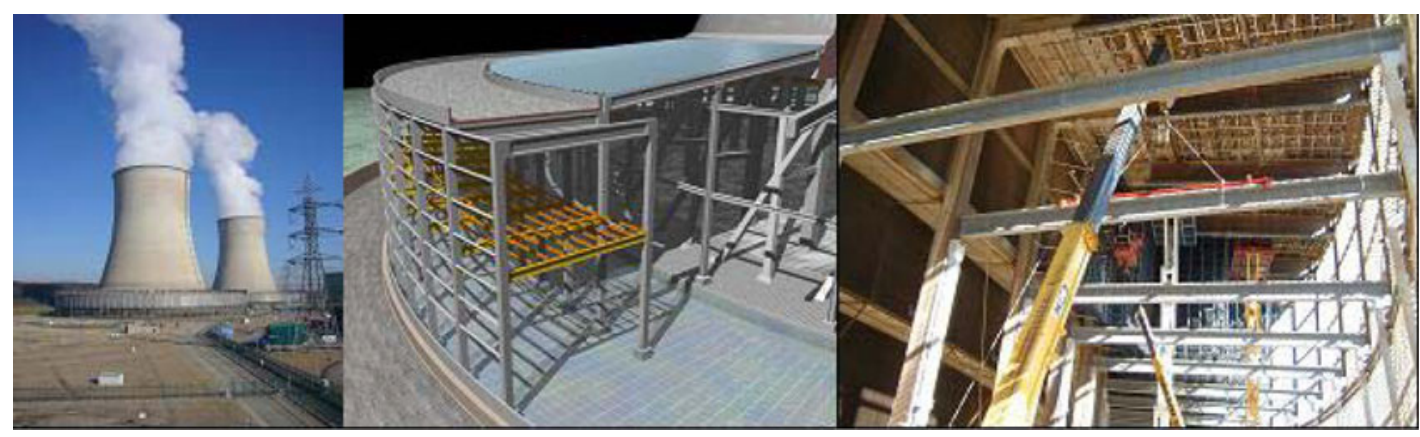

Figure 1. Cross-flow cooling towers and renovation of the exchange device.

limit the additional weight due to the soil properties and the risk of settlement, it was chosen to construct this additional superstructure from a grillage of precast pre-stressed UHPFRC beams and girders. This was considered to be a pioneering large-scale industrial application of UHPFRC in France [1, 2]. The girders were fabricated between 1996 and 1998, partly using ${ }^{\circledR}$ RPC (UHPFRC material developed in partnership by Bouygues, Lafarge and Rhodia companies, presently used as the material for structural applications within ${ }^{\circledR}$ Ductal range) and partly using ${ }^{\circledR}$ BSI (UHPFRC material developed by Quillery, presently distributed by Eiffage under the name BSI-Ceracem). Installation of the beams took place during plant outage directly above the cold water basin once drained (Figure 1).

Two UHPFRC girders were placed as durability testing specimens at the ground level of cooling tower 1 in order to investigate their ageing in the aggressive atmosphere. The girders are superimposed with tendons facing each other; the set-up includes a sustained loading produced by a central prestressing bar which induces tension up to $14 \mathrm{MPa}$ within the outer chord of the pre-stressed flange. The girders are supported at the edge of the cool water basin and are not immersed in it. Shorter specimens above these girders are used to assist in surveying the effectiveness of different protective systems against corrosion at the end of the tendons. The girders consiste of RPC (with thermal treatment), and were cast by the end of May 1996 in the Sablons factory, Longjumeau, Paris. The high compressive strength (about $200 \mathrm{MPa}$ ) is the result of a reduced water to cement ratio (down to 0.19), the cement content representing $30.6 \%$ of the material without fibres. The fibre content is $161 \mathrm{~kg} / \mathrm{m}^{3}(2.1 \%$ of the volume content).

Regading thermal and moisture conditions, the girders are almost permanently (except during breaks in operation) exposed to warm rainwater. The average water temperature is $35^{\circ} \mathrm{C}$ and it is assumed that surrounding relative humidity is $100 \%$. Freeze mitigation prevents the temperature of the cold water basin falling below $10^{\circ} \mathrm{C}$ in winter. It is assumed that girders at short distance from the basin would experience approximately the same temperature on average as the others. However, their ends at the edge of the basin close to the outer edge of the cooling tower are at the limit of the zone exposed to to water drops, and ice could form, depending on the winter conditions (rather mild during the last 10 years). Chemical attacks also need to be considered. The surrounding water has a pH-level between 7 and 7.5. It is furring water: the girders facings, and also those of reinforced concrete piers supporting the external superstructure and the chimney of the cooling tower, have been entirely and rapidly covered by a calcium deposit. Analysis of the water of the cooling circuit indicates a maximum chloride content between 1 and $2 \mathrm{~g} / \mathrm{l}$, and a sulphate content of about $500 \mathrm{mg} / \mathrm{l}$. In comparison, in an analysis of water of Mosel River, a pH of 7.8 and concentrations of about $400 \mathrm{mg} / \mathrm{l}$ for chlorides and $100 \mathrm{mg} / \mathrm{l}$ for sulphates were observed. As part of a united effort carried out by the plant operator, EDF experts and AFGC task group for UHPFRC, it was decided to take advantage of the February 2008 operation break, some 10 years after putting back to operation the retrofitted cooling tower, and a new inspection was planned including the taking of samples. The purpose of the cored sample specimens was to help to quantitatively 


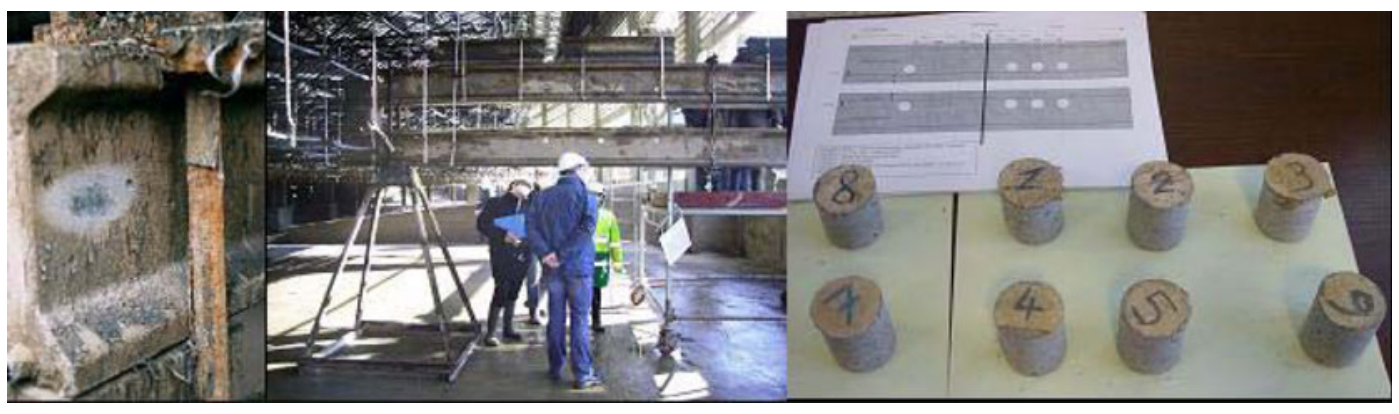

Figure 2. UHPFRC girders warning specimens and drilled specimens.

characterise possible in-situ ageing of the UHPFRC structures, which are among the oldest available in France for such purpose [3] (Figure 2).

The bases of the drilled cylinders and the visual external aspect of the girders facings confirm the presence of a calcium deposit. Where unprotected, tendons ends are corroded. However, thorough examination of drilled surfaces showed that the fibres remained sound, except where they are raised out of the outer surface in the angles or at free (unformed) surfaces.

Both porosity accessible to water and capillary water absorption were measured on sample \#5 in application of methods recommended in [4]. The values obtained are $4.3 \%$ and from 0.025 to $0.035 \mathrm{~g} / \mathrm{cm}^{2}$ respectively. The water absorption is approximately 10 times lower than usually observed for high performance concrete. Altogether, this value complies with known measures indicated in AFGC Recommendations [5]. Carbonation depth was evaluated in the first instance with a widely used indicator (phenolphthalein) on the drilled cylinder \#6 previously split transversely in two parts. On the first side, corresponding to the girder web facing with higher tartar layer thickness, the thickness of the external zone with $\mathrm{pH}$ lower than 9 is $1 \mathrm{~mm}$. On the other side, carbonated depth is non measurable. An attempt was made to obtain a more quantitative evaluation, with quantitative determination of the $\mathrm{pH}$ value in slices sawn from the samples. Along the height of sample \#8, $6 \mathrm{~mm}$-thick slices were cut, except for the first (thicker) one. Each sample was ground in order to obtain about $15 \mathrm{~g}$ of material, from which $\mathrm{pH}$ was determined following the method described in [6], namely using $10 \mathrm{ml}$ of a solution obtained with $15 \mathrm{~g}$ of the ground material and $15 \mathrm{~g}$ of water. Before the measures were taken, the $\mathrm{pH}$-meter was calibrated with reference solutions of $\mathrm{pH}$ equal to 7 and 12.45. The $\mathrm{pH}$-value of each slice was close to 12.3 and variations along the thickness of the web were insignificant, revealing sound (non-carbonated) concrete.

An attempts was made to quantify the possible penetration of chlorides, which are present at a relatively high content in the water of the thermal exchange circuit, by a chemical dosage of the concrete slices relevant to the surface or the core of sample \#1 drilled from the UHPFRC girder web. The chloride ion dosage was carried out according to a potentiometric method using a $0.01 \mathrm{~mol} / 1$ solution of silver nitrate. The procedure for free chlorides dosage derives from works described in [7]. The quantity of chloride ions was found to be as low as $0.1 \mathrm{~g} \mathrm{Cl}^{-}$per $100 \mathrm{~g}$ of cement, which is the precision limit of the method due to the low material quantities available. This limit is compared to the threshold generally admitted for induction of the reinforcement corrosion, namely $0.4 \mathrm{~g} \mathrm{Cl}^{-}$per $100 \mathrm{~g}$ of cement. It can thus be concluded that chloride penetration within UHPFRC members was insignificant, with respect to the risk of chloride-induced corrosion, as a result of both the rather low chlorides content of the surrounding water and from the low expected transfer coefficients of the UHPFRC materials. Any sulfate penetration has been observed in concrete samples.

Three specimens were used to quantify the possible evolution over time of UHPFRC mechanical characteristics. Drilled specimens \#2, 3 and 4 were tested as cylinder shaped samples to see whether they met acceptable test requirements. Following this drilled specimens were obtained again, to avoid 


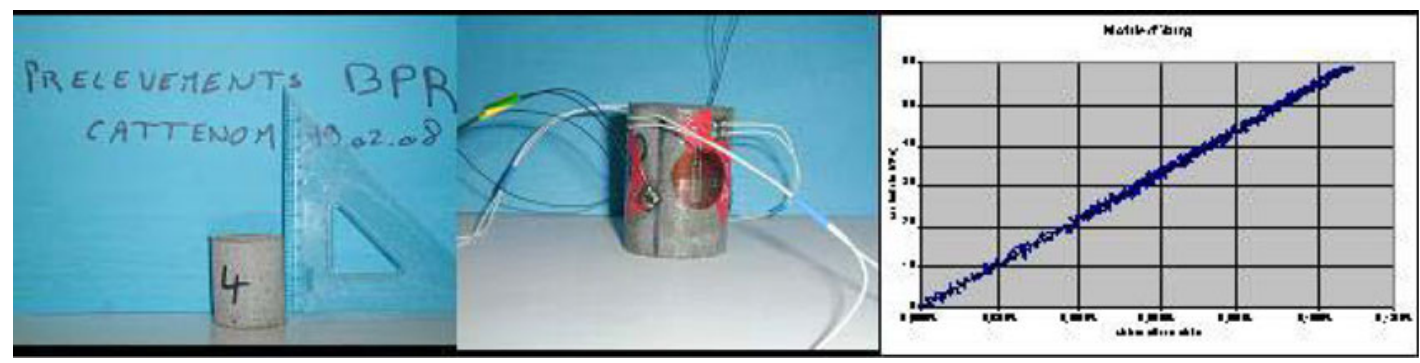

Figure 3. Specimens for mechanical test and strains vs. stress curve example.

off-centering artifacts during the compressive tests, which led to a final diameter equal to $36 \mathrm{~mm}$. After mechanical rectification, which was carried out to ensure that the specimen surface was made smooth enough with respect to expected strength, the specimen height reached $48 \mathrm{~mm}$. The resulting aspect ratio, namely 1.33 , is slightly lower than the generally accepted geometrical range, avoiding strength overestimation with respect to uni-axial compression (size effect due to ends confinement). Cylinders obtained were equipped with 3 pairs of (longitudinal and transverse) strain gauges, $10 \mathrm{~mm}$-long, glued at $120^{\circ}$ along the cylinder outer surface, in order to determine Young's modulus and Poisson's ratio. Thesewere correctly achieved for two specimens only, while compressive strength was measured for the three cylinders (Figure 3).

Material characterisation was carried out at the age of 7 days after casting (which is also after the thermal treatment), on cylinders $70 \mathrm{~mm}$ in diameter. Direct comparison with data measured on drilled specimens at 10 years was undertaken to mitigate a possible favorable size effect for the smaller specimens. In any case, reference initial characteristics were as follows: Compressive strength: 207.8 MPa, Young's modulus: 56.0 GPa, Poisson's ratio: 0.21. Results at 10 years on the drilled specimens were as follows: Compressive strength: 240.3 MPa, Young's modulus: 54.4 GPa and Poisson's ratio : 0.21 . For the loading cycles between $5 \%$ and $30 \%$ of the expected maximum load, the linearity of the (longitudinal and transverse) strains vs. stress curves was as excellent, which favours the quality of Young's modulus and Poisson's ratio determination and demonstrates the absence of internal material damage. Given the usual deviation in these types of tests however, it cannot be concluded to that there is a significant evolution of Young's modulus and Poisson's ratio. For the strength, a long-term increase is unlikely, given the difference in size and aspect ratio of the two series of specimens. It can therefore be stated that the mechanical characteristics and so the design values are sufficiently stable to confirm the high durability potential of UHPFRC.

\section{HIGH SLAG CONTENT CONCRETE FEEDBACK}

This case study concerns a pump station of a nuclear power plant in Northern France built in the 1970's. This case deals with concrete containing a cement with a high slag content (about 40\%), which is part of a structure exposed to industrial and marine salts for 30 years. Drilling of samples is illustrated in the Figure 4 . The concrete contains $350 \mathrm{~kg} / \mathrm{m} 3$ of cement and the water to cement ratio is approximately 0.5 . The porosity accessible to water was measured according to [4] and the result obtained was $12.6 \%$. The apparent chloride diffusion coefficient was measured by migration method under transient electric field (Tang-Nilsson method). The mean apparent chloride diffusion coefficient obtained was $1.210^{-12} \mathrm{~m}^{2} / \mathrm{s}$. Compressive strength was measured on three samples. The mean compressive strength obtained was 49.3 MPa. The carbonation depth was measured on three samples using phenolphthalein.

The results show that the mean carbonation front is located at an estimated depth of $15-20 \mathrm{~mm}$. We can consider the depth of carbonation as low in view of the age of concrete. The determination of total chlorides content was carried out by potentiometric method on a sample. Measurements were 


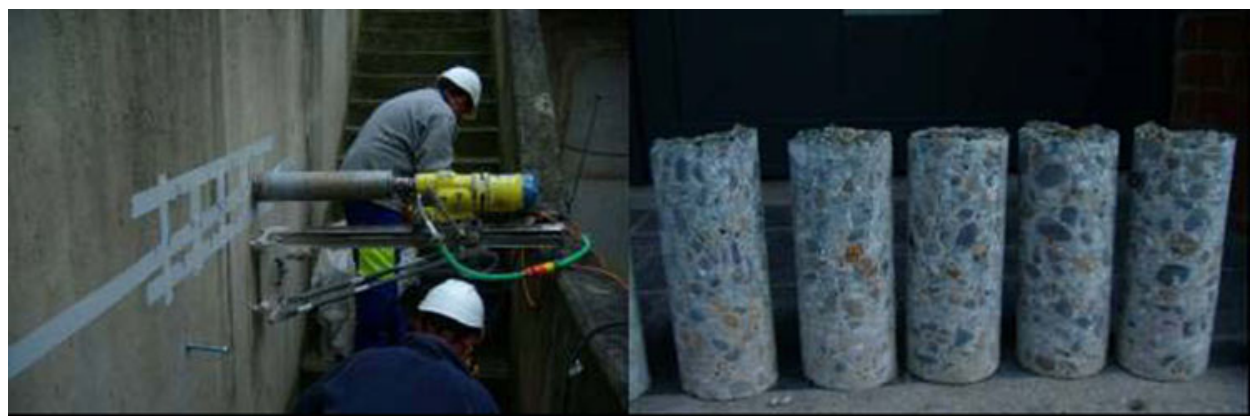

Figure 4. Drilling operations.

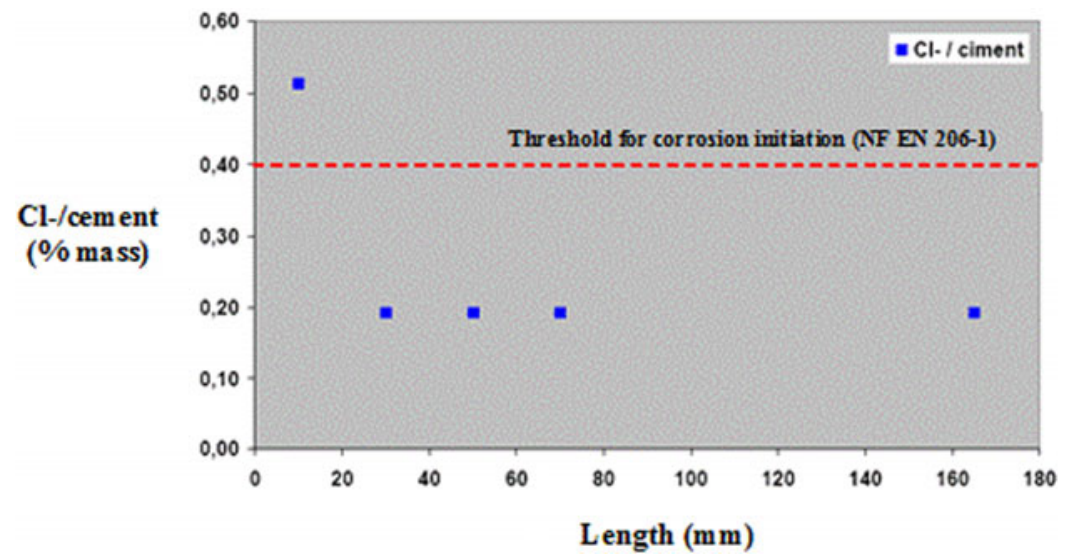

Figure 5. Total chlorides content profile.

performed on four slices of $20 \mathrm{~mm}$ thickness in order to have a detailed profile of the first $80 \mathrm{~mm}$. A fifth measure was taken to determine the chloride content at the heart of concrete $(160-180 \mathrm{~mm})$. The results are illustrated in Figure 5.

The total chlorides content is relatively high ( $0.5 \%$ of cement mass) in concrete surface. This reflects a chloride supply associated with the marine environment. This high content can also connected with a high content of chloro-aluminates reflecting fixation of chlorides with the aluminates of the cement (Figure 6). Deeper down the chlorides content (around $0.2 \%$ of the cement mass) is low and well below the limit of $0.4 \%$ according to the French standard NF EN 206-1. This limit of $0.4 \%$ is defined for reinforced concrete and is typically the threshold for consideration of corrosion initiation. This limit can also be increased to $0.65 \%$ for concrete containing cements with high slag content (facilitating the chemical fixation of chlorides). In conclusion aggressive agents have not reached the specified reinforcement cover after more than 30 years of exposure, thus it can be concluded that the carbonationinduced/chlorides induced corrosion risk at present is very limited.

A high sulfate content $\left(\mathrm{SO}_{3}>4 \%\right.$ of cement content) has been measured only in concrete surface (depth $<20 \mathrm{~mm}$ ). Deeper down the sulfate content is low (around $2.5 \%$ of cement content).

\section{PERFORMANCE-BASED APPROACH}

This section presents a basic theoretical method used by EDF for quantifying the durability of a given concrete. This method applies the French performance-based approach (developed by Association 

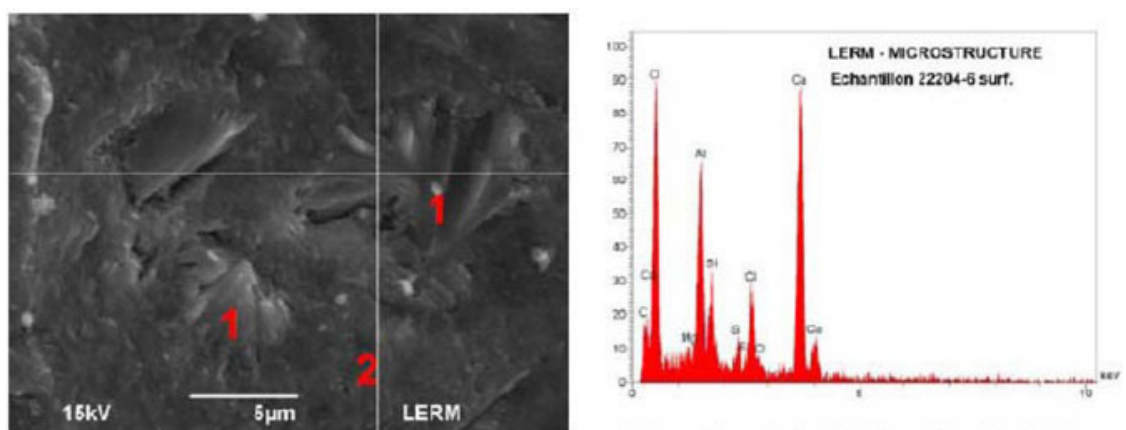

Figure 6. SEM observation of chloro-aluminates (1) and CSH (2) - XRD Analysis of chloro-aluminates.

\begin{tabular}{|c|c|c|c|c|c|}
\hline & \multicolumn{5}{|l|}{ Classes } \\
\hline "Potential" durability & Very low & Low & Medium & High & Very high \\
\hline Porosity accessible to water $\Phi(\%)$ & $>16$ & 14 to 16 & 12 to 14 & 9 to 12 & 6 to 9 \\
\hline Electrical resistivity $\rho(\mathrm{k} \Omega . \mathrm{cm})$ & $<5$ & 5 to 10 & 10 to 25 & 25 to 50 & $>50$ \\
\hline $\begin{array}{l}\text { Effective chloride diffusion coefficient } \\
\text { Deff }(10-12 \mathrm{~m} 2 / \mathrm{s})\end{array}$ & $>8$ & 2 to 8 & 1 to 2 & 0.1 to 1 & $<0.1$ \\
\hline $\begin{array}{l}\text { Apparent chloride diffusion coefficient } \\
\text { Dapp }(\text { mig) }(10-12 \mathrm{~m} 2 / \mathrm{s}) \\
\text { (measured by means of a migration test) }\end{array}$ & \multirow{2}{*}{$>50$} & \multirow{2}{*}{10 to 50} & \multirow{2}{*}{5 to 10} & 1 to 5 & $<1$ \\
\hline $\begin{array}{l}\text { Apparent chloride diffusion coefficient } \\
\text { Dapp(dif) }(10-12 \mathrm{~m} 2 / \mathrm{s}) \\
\text { (measured by means of a diffusion test) }\end{array}$ & & & & \multicolumn{2}{|l|}{$<5$} \\
\hline $\begin{array}{l}\text { Apparent gas permeability Kapp(gas) } \\
(10-18 \mathrm{~m} 2) \\
\text { (with input pressure }=0.2 \mathrm{MPa} \text { and after } \\
\left.\text { drying at } 105^{\circ} \mathrm{C}\right)\end{array}$ & $>1000$ & $\begin{array}{l}300 \text { to } \\
1000\end{array}$ & 100 to 300 & 10 to 100 & $<10$ \\
\hline $\begin{array}{l}\text { Liquid water permeability kl (10-18 m2) } \\
\text { (with measurement of flow rate after } \\
\text { saturation) }\end{array}$ & $>10$ & 1 to 10 & 0.1 to 1 & $\begin{array}{l}0.01 \text { to } \\
0.1\end{array}$ & $<0.01$ \\
\hline $\begin{array}{l}\text { Type of concrete (indicative) } \\
\text { (the number indicates the 28-day } \\
\text { characteristic compressive strength) }\end{array}$ & & $\begin{array}{l}\mathrm{C} 25 \text { to } \\
\mathrm{C} 35\end{array}$ & $\begin{array}{l}\text { C30 to } \\
\text { C60 }\end{array}$ & $\begin{array}{l}\text { C55 to } \\
\text { C80 }\end{array}$ & $>\mathrm{C} 80$ \\
\hline
\end{tabular}

Figure 7. Example of the "potential" durability determination for the concrete containing a high slag content (in bolt style in the figure).

Française de Génie Civil in 2004) [4] as a tool box defining the "potential durability" of a given concrete and checking the adequacy between durability indicators, monitoring parameters and the specified service life.

The case of the high slag content concrete is shown. The authors have directly associated the durability indicators measured on the concrete samples with the thresholds proposed in the performancebased approach. Firstly, the "potential" durability of the concrete can be defined according to durability indicators. Figure 7 illustrates an example of application for the high slag content concrete. It is noted that this concrete has a medium/high "potential" durability class.

UHPFRC should have the highest "potential" durability class but it is evident that the thresholds of the performance-based approach do not really consider this kind of concrete (the water porosity measured on UHPFRC is lower than $6 \%$ which is the limit of the highest class). 
AMP 2010

\begin{tabular}{|c|c|c|c|c|}
\hline Environment type $\rightarrow$ & \multirow{2}{*}{\multicolumn{2}{|c|}{$\begin{array}{c}5 \\
\text { Exposure to spraying of mariné } \\
\text { or deicing salts }\end{array}$}} & \multirow{3}{*}{$\begin{array}{l}\text { Immersion in } \\
\text { seawater }\end{array}$} & \multirow{3}{*}{$\frac{7}{\text { Tidal zone }}$} \\
\hline Target service life & & & & \\
\hline$\downarrow$ & $5.1\left(c_{s} \leq 10\right.$ g.L & $5.2\left(c_{s} \geq 100\right.$ g.L $\left.L^{-1}\right)$ & & \\
\hline$<30$ years & $\phi<0.16$ & $\bullet \phi<0.14$ & $\bullet \phi<0.15$ & $\bullet \phi<0.14$ \\
\hline from 30 to 50 years & $\bullet \phi<0.15$ & $\bullet \phi<0.11$ & $\bullet \phi<0.13$ & $\bullet \phi<0.11$ \\
\hline from 50 to 100 years & 14 & & $\begin{array}{l}\cdot \phi<0.13 \\
\cdot \mathrm{D}_{\text {app }(\operatorname{mig})}<7\end{array}$ & 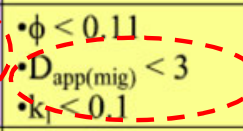 \\
\hline $\begin{array}{c}\text { from } 100 \text { to } 120 \\
\text { years }\end{array}$ & $\begin{array}{l}\phi<0.12 \\
\cdot \mathrm{D}_{\text {app(mig) }}<2 \\
\cdot \mathrm{k}_{\mathrm{I}}<0.1\end{array}$ & $\begin{array}{l}\cdot \phi<0.09 \\
\cdot \mathrm{D}_{\text {app(mig) }}<1 \\
\cdot \mathrm{K}_{\text {app (gas) }}<30 \\
\cdot \mathrm{k}_{\mathrm{l}}<0.01\end{array}$ & $\begin{array}{l}\cdot \phi<0.12 \\
\cdot \mathrm{D}_{\text {app }(\text { mig })}<5\end{array}$ & $\begin{array}{l}\cdot \phi<0.10 \\
\cdot \mathrm{D}_{\text {app(mig) }}<2 \\
\cdot \mathrm{K}_{\text {app(gas) }}<100 \\
\cdot \mathrm{k}_{1}<0.05\end{array}$ \\
\hline$>120$ years & $\begin{array}{l}\cdot \phi \leq \theta . \theta 9-- \\
\cdot \mathrm{D}_{\text {app(mig) }}<10 \\
\cdot \mathrm{K}_{\text {app (gas) }}<-3 \theta- \\
\cdot \mathrm{k}_{1}<0.01\end{array}$ & $\begin{array}{l}\cdot \phi<0.09 \\
\cdot \mathrm{D}_{\text {app(mig) }}<1 \\
\cdot \mathrm{K}_{\text {app(gas) }}<30 \\
\cdot \mathrm{k}_{\mathrm{I}}<0.01\end{array}$ & $\begin{array}{l}\cdot \phi<0.09 \\
\cdot \mathrm{D}_{\text {app(mig) }}<1\end{array}$ & $\begin{array}{l}\cdot \phi<0.09 \\
\cdot \mathrm{D}_{\text {app(mig) }}<1 \\
\cdot \mathrm{K}_{\text {app(gas) }}<30 \\
\cdot \mathrm{k}_{\mathrm{l}}<0.01 \\
\end{array}$ \\
\hline
\end{tabular}

Figure 8. Example of determination of the target service life for the concrete containing a high slag content.

Finally the durability indicators can be used to assess the target service life in relation with the environment of the concrete. This performance-based approach considers a generic type of reinforced concrete structure with a given concrete cover. The given concrete cover is $30 \mathrm{~mm}$ for a carbonationinduced risk or $50 \mathrm{~mm}$ for chlorides-induced corrosion risk. The Figure 8 illustrates the application of this generic tool with the high slag content concrete according to chloride exposures.

From the figure above it can be seen that the example of the high slag content concrete gives a target service life from 50 to 100 years considering the exposure of the case study (exposure to marine salts with a chlorides concentration $<10 \mathrm{~g} / \mathrm{l}$ ). Moreover, it can be noted that the properties of this concrete could satisfy some more aggressive environments : for example the porosity and the apparent diffusion coefficient would satisfy a target service life from 50 to 100 years for an immersion in seawater. This conclusions are valid only in the case of the generic type of structure for the considered performancebased approach. If the studied structure was different (case of pre-stressed concrete, different concrete cover, ... ) a comprehensive study shall be done for considering the actual configuration (for example for the UHPFRC case study because of a reduced concrete cover and a pre-stressed concrete configuration). The AFGC document [4] indicates the possible ways to conduct such studies. Namely, the "ultra-low" diffusion coefficients of UHPFRC can find a valuable application either in ensuring an extended lifespan for a given cover, or in reducing the cover thickness while maintaining the required lifespan. And the field experience of the pre-stressed UHPFRC girders detailed in section 2, with non-measurable chemical ingress after 10 years, keeps fully consistent with the expected extremely low risk of steel corrosion in these components for more than 100 years even with a $22 \mathrm{~mm}$-cover.

The application of the performance-based approach is consistent with the penetration depth of aggressive agents actually observed in the two case studies.

\section{PROSPECTS: SIMULATION METHODS DEVELOPMENTS}

It is EDF's research and development commitment to develop materials or structural simulation tools for enhancing expertise and risk-based decision making. For example LEO was developed for the service 


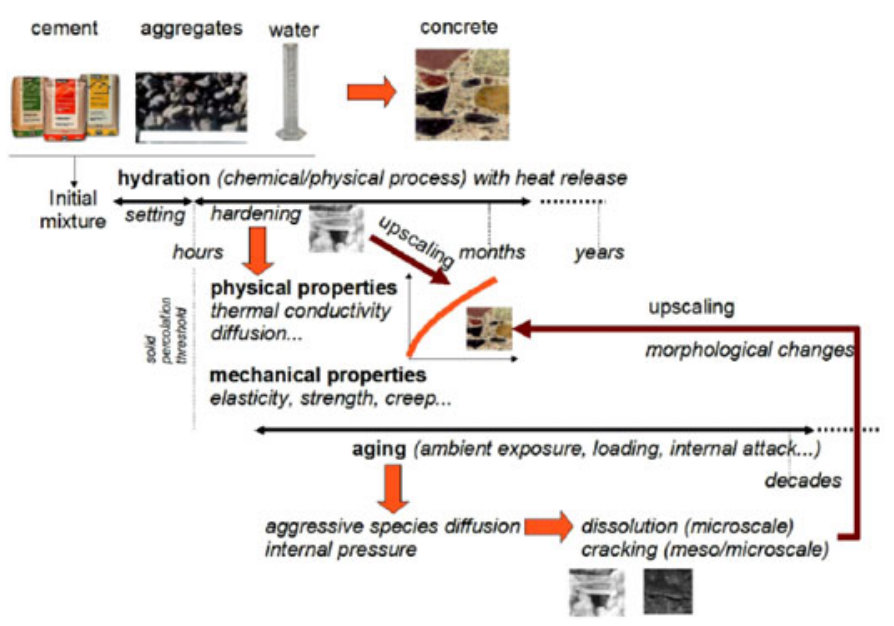

Figure 9. Illustration of $\mathrm{Vi}(\mathrm{CA}) 2 \mathrm{~T}$ scheme.

life prediction of corroded reinforced concrete infrastructures [4] and could be used to conduct some comprehensive studies as mentioned in the last section. This section summarises current developments of Vi(CA)2T (Virtual Cement and Concrete Aging Analysis Toolbox) for the derivation of the overall properties of a concrete as a function of the mix design. It shows the prospects being considered by EDF in order to extend the use of performance-based approaches. Both case studies presented in this paper have not yet been simulated.

The aim of $\mathrm{Vi}(\mathrm{CA}) 2 \mathrm{~T}$ is to take advantage of the significant scientific advances made in the last decade in the field of cement chemistry and micro-mechanics of random media and to build an end-user toolbox functioning for a "generic recipient".

The developments of $\mathrm{Vi}(\mathrm{CA}) 2 \mathrm{~T}$ started in 2007 and focused on the modeling of hydration, elasticity, creep, shrinkage and leaching (Figure 9). Modelling hydration is required to account for various chemical reactions (calcium silicate, aluminate,...), different kinetics periods (induction, nucleation-growth, diffusion) and thermo-activation. Then, the model of microstructure is related to a homogenisation scheme comprising different kinds of particles (spheres, spheroids, multi-layered spheres, ...) and different topological options (particles in the matrix,...).

$\mathrm{Vi}(\mathrm{CA}) 2 \mathrm{~T}$ has the capability to derive the effect of porosity increases (leaching of cement, cracking) on the overall properties of concrete. $\mathrm{Vi}(\mathrm{CA}) 2 \mathrm{~T}$ has been designed to be compatible with probabilitybased analysis and can compute uncertainty propagation while upscaling the mechanical properties (e.g. effect of variable mechanical properties of aggregate on concrete) or simulating the effect of variable mix on hardened concrete properties.

Initial developments have focussed on the modeling of the physical properties (porosity, Young's modulus,...) and creep concerning old concretes with Portland cement. The Figure 10 shows an example of porosity vs. hydration degree curve obtained for a concrete at two different scales (matrix and concrete scales).

This kind of model may be of great interest with the prospect of assessing the durability through the prediction of indicators that could complement experimental data for the application of the performance-based approach. To this end $\mathrm{Vi}(\mathrm{CA}) 2 \mathrm{~T}$ is currently under development for predicting the durability indicators ( (i.e. containing fly ash, slag, silica fume,...). 

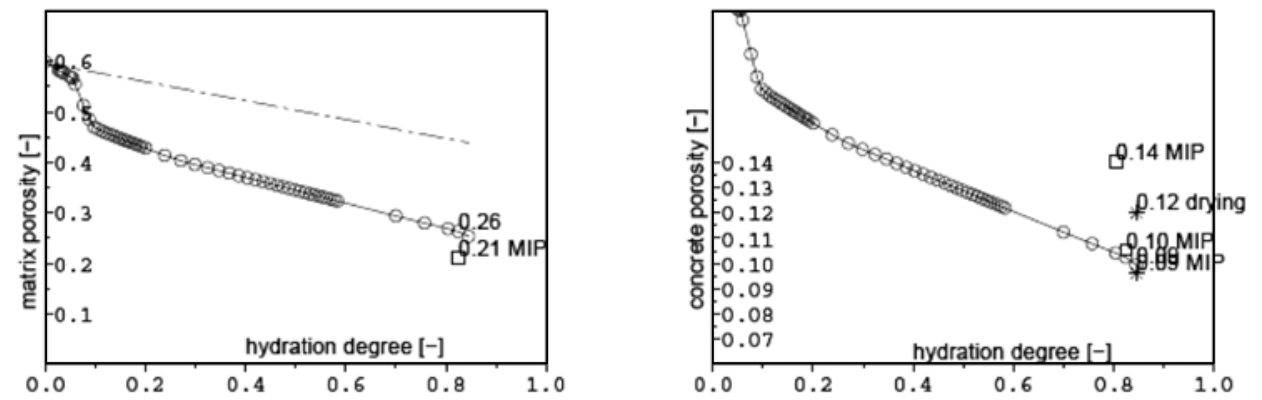

Figure 10. Examples of porosity vs. hydration degree curves for two different scales (matrix on the left and concrete on the right).

\section{CONCLUSIONS}

The present study focussed on the diagnosis of a UHPFRC and a concrete containing a high slag content exposed to their environment for many years. Measurements of carbonation and chlorides fronts have concluded that the carbonation-induced/chlorides induced corrosion risk at present was very limited for the two case studies. These observations have been confirmed by the application of a theoretical performance-based approach. This study also showed that the assessment of the "potential" durability of a concrete shall consider several factors to be optimal. For example it has been found for the concrete containing a high slag content that its properties (porosity, diffusion coefficient...) could well protect against corrosion even if this concrete contains a low $\mathrm{Ca}(\mathrm{OH}) 2$ content (the risks of corrosion are supposed to be more important for this kind of concrete).

Finally this study has demonstrated that the performance-based approach can provide an additional point of view by assessing a concrete's "potential" durability and estimating the target service life. This approach fits directly into the problems of management of structures and can be of particular interest when some data on concrete compositions are missing. The simulations methods currently under development by EDF such as $\mathrm{Vi}(\mathrm{CA}) 2 \mathrm{~T}$ would extend the possibilities to use this kind of approach.

The investigations on UHPFRC detailed in these paper were only possible thanks to the support of Cattenom power plant managers and experts from EDF company, among them D. Chauvel, and members of the AFGC (French branch of RILEM, fib and IABSE) group on UHPFRC, among them the group convener J. Resplendino and A. Simon from Eiffage who coordinated the samples coring. V. Baroghel-Bouny and L. Divet from LCPC, and M. Carcasses from LMDC, shall be mentioned for their fruitful advice in elaborating the experimental investigation program. Last but not least, the technical help of V. Bouteiller, A. Pavoine, A. Deman, G. Platret, F. Martineau, F.-X. Barin, L. Lauvin, B. Duchesne, A. Plantet, F. Lespinasse, J. Dauthuille at LCPC for the specimens preparation and analysis is gratefully acknowledged.

The investigations on the concrete containing a high slag content were performed thanks to a EDF/Holcim collaboration. The authors acknowledge C. Charron from Holcim for his fruitful advice in elaborating the experimental program and A. Ammouche from LERM for the specimens analysis.

\section{References}

[1] G. Birelli, D. Chauvel, J. Dugat, R. Adeline, A. Bekaert, La technique française du béton, AFPCAFREM, 13th FIP congress, pp. 230-213 (1998)

[2] F. Dutalloir, T. Thibaux, G. Cadoret, G. Birelli, La technique française du béton, 13th FIB congress, AFPC-AFREM, pp. 25-32 (1998) 
[3] F. Toutlemonde, V. Bouteiller, A. Deman, G. Platret, A. Pavoine, B. Duchesne, L. Lauvin, M. Carcasses, M. Lion, CONSEC 10, June 7-9 (2010)

[4] V. Baroghel-Bouny ed., Documents scientifiques et techniques AFGC, in french (2004), in english (2007)

[5] J. Resplendino \& J. Petitjean eds, Documents scientifiques et techniques AFGC (2002)

[6] W. Yeih, J. Chang, Construction and Building Materials 19 (2005)

[7] M. Castellote, C. Andrade, Materials and structures 34 (2001) 